\title{
Original Article \\ Psychometric Properties of the Heart Disease Knowledge Scale: Evidence from Item and Confirmatory Factor Analyses
}

Submitted: 27 Jan 2016

Accepted: 19 Apr 2016

Online: 30 June 2016

\author{
Bee Chiu Lim,2, Yee Cheng KueH ${ }^{1}$, Wan Nor Arifin ${ }^{1}$, Kok Huan \\ $\mathrm{NG}^{3}$ \\ 1 Unit of Biostatistics and Research Methodology, School of Medical Sciences, \\ Universiti Sains Malaysia, 16150 Kubang Kerian, Kelantan, Malaysia \\ 2 Clinical Research Centre, Hospital Tengku Ampuan Afzan, Jalan Air Putih, \\ 25100 Kuantan, Pahang, Malaysia \\ 3 KPJ Kuantan Specialist Hospital, Jalan Alor Akar, 25250 Kuantan, Pahang, \\ Malaysia
}

To cite this article: Lim BC, Kueh YC, Arifin WN, Ng KH. Psychometric properties of the heart disease knowledge scale: Evidence from item and confirmatory factor analyses. Malays J Med Sci. 2016; 23(4): 33-45. doi: 10.21315/ mjms2016.23.4.5

To link to this article: http://dx.doi.org/10.21315/mjms2016.23.4.5

\begin{abstract}
Background: Heart disease knowledge is an important concept for health education, yet there is lack of evidence on proper validated instruments used to measure levels of heart disease knowledge in the Malaysian context.

Methods: A cross-sectional, survey design was conducted to examine the psychometric properties of the adapted English version of the Heart Disease Knowledge Questionnaire (HDKQ). Using proportionate cluster sampling, 788 undergraduate students at Universiti Sains Malaysia, Malaysia, were recruited and completed the HDKQ. Item analysis and confirmatory factor analysis (CFA) were used for the psychometric evaluation. Construct validity of the measurement model was included.

Results: Most of the students were Malay (48\%), female (71\%), and from the field of science (51\%). An acceptable range was obtained with respect to both the difficulty and discrimination indices in the item analysis results. The difficulty index ranged from $0.12-0.91$ and a discrimination index of $\geq 0.20$ were reported for the final retained 23 items. The final CFA model showed an adequate fit to the data, yielding a 23-item, one-factor model [weighted least squares mean and variance adjusted scaled chi-square difference $=1.22$, degrees of freedom $=2, P$-value $=0.544$, the root mean square error of approximation $=0.03(90 \%$ confidence interval $=0.03,0.04)$; close-fit $\mathbf{P}$-value $=>0.950]$.

Conclusion: Adequate psychometric values were obtained for Malaysian undergraduate university students using the 23-item, one-factor model of the adapted HDKQ.
\end{abstract}

Keywords: heart disease, knowledge, factor analysis, universities, psychometrics

\section{Introduction}

Cardiovascular disease (CVD) such as heart disease is the number one cause of death in the world (1) including Malaysia (2). Heart disease continues to result in high mortality and hospital admission cases $(3,4)$. The prevalence of heart disease-related risk factors e.g. hypertension, is much less apreciated in young adults (5).

However, there was an increase in body mass index, $\geq 85 \%$ percentile from $15-34 \%$ in students aged 12-19 years (6) in the United States, while hypertension $\geq 95 \%$ percentile increased from $3-4 \%$ (7). In 2010, an increased prevalence of pre-hypertension and hypertension was demonstrated in a study on Malay adolecence in Putrajaya, Malaysia (8) of $11 \%$ and $12 \%$ respectively. Increasing blood pressure in children and adolescents over the last decade was partially attributed to the increased prevalence of overweight (9). 
Strong evidence from pathobiological studies suggests that atherosclerotic CVD begins at a young age $(10,11)$. Thus, early health education e.g. knowledge about heart disease programmes play an important role in disease prevention in young adults. Hunt (12) defined knowledge as the characteristic of a person who influences his or her own behavioural potential. Health knowledge is prerequisite to making health decisions and initiating behaviour change $(13,14)$. A suboptimal level of knowledge about CVD was highlighted in earlier studies on young adults (15-17). Thus, a psychometrically sound instrument is required to determine individual health knowledge of heart disease and to apply it to disease prevention.

Research on heart disease knowledge, with the inclusion of healthy adults or at-risk populations, has mainly focused on risk factors $(14,18)$. Although numerous studies had been conducted on the heart disease knowledge scale, few have reported information on the psychometric properties of the instrument used (19-21). In Malaysia, only a few publications exist on heart disease knowledge, while information has not been published on the instrument's reliability or validity $(22,23)$.

The measurement of heart disease knowledge is very broad, and there may be variation between studies. As young adults are at optimal risk of heart disease, their knowledge in this regard should be assessed according to important domains, such as medical treatment, symptoms and epidemiology, in order to acquire an accurate picture of heart disease knowledge (24). Young adults' understanding of the treatment, symptoms and epidemiology of heart disease is important because it influences the identification and management of the disease in future.

Psychometric properties include an instrument's validity and reliability (25). "Validity" is defined as the degree to which an instrument measures what it is intended to measure (26). "Reliability" is the extent to which repeated measurements of a relatively stable phenomenon yield the same or a very similar result (27). The instrument developed by Bergman et al. (24), the Heart Disease Knowledge Questionnaire (HDKQ), was tested for its reliability and validity. HDKQ measures knowledge of heart disease among university students, and covers a wide range of knowledge concepts, e.g. medical, symptom, dietary, risk factors and epidemiology. It has been claimed to be reliable and valid among university student populations in the
United States, and has been used widely in other studies $(15,28)$. Moreover, it covers a wide range of difficulty items, based on a comprehensive review of currently available instruments used to determine heart disease knowledge, as means to improving the HDKQ items. However, the value of its psychometric properties has not been properly tested in Malaysian undergraduate students. Thus, it is possible that the results obtained in this study would differ to those obtained in studies conducted in the United States.

Therefore, the aim of this study was to evaluate the psychometric properties of the English version of the adapted HDKQ, designed to measure knowledge related to heart disease in Malaysian undergraduate students. Specifically, the intention was to examine each individual item included in the HDKQ by item analysis and then to determine the factor structure of HDKQ via confirmatory factor analysis (CFA).

\section{Methods}

\section{Study design and procedures}

A cross-sectional, survey design was used in this study conducted at Universiti Sains Malaysia (USM) from November 2014 to January 2015. The questionnaire was reviewed by cardiologist, physician, psychometric and psychology experts to ensure that the contents were appropriate to Malaysian culture. This study involved the psychometric testing of an inventory based on item level (item analysis) and scale level (CFA) in a Malaysian population.

Participants were briefed on the purpose of the study, the procedures and the confidentiality of their responses. They were informed that their participation in the study was voluntary, and had the opportunity of reviewing the questionnaire before agreeing to participate in the study. The completed surveys were collected immediately prior to the students leaving the lecture hall.

\section{Participants}

This research recruited Malaysian undergraduate university students as research participants. The participants were recruited from the three campuses (Health, Main and Engineering) at USM. A cluster sampling technique, with probability proportional to the cluster size, was applied. The schools were treated as a cluster. Eight schools were randomly selected 
Original Article | Psychometric properties of the heart disease knowledge scale

from 24 schools at USM. A higher proportion of study participants was drawn from schools with a higher number of registered students than that from schools with a lower number.

Due to the restricted information from Registrar Office of USM and the availability of students in class are dynamic, not all students were selected from each cluster. The weightage was given to each school, based on the population of students enrolled in the year 2014. Thereafter, first- to third-year undergraduate students were purposively selected from the selected eight schools from the final school cluster. Eight hundred and thirty-seven students were invited to participate in the study. The completed questionnaire was returned to the researcher by 788 students, and the response rate was $94 \%$.

\section{Heart Disease Knowledge Questionnaire (HDKQ) instrument}

The self-administered English version of the HDKQ comprises 30 items as follows: dietary (6 items), epidemiology (4 items), medical (7 items), risk factor (9 items) and heart attack symptom (4 items). There were three possible answers to each statement of "True", "False" and "Don't know" (24).

The response of the participants was coded as o for an incorrect answer or "Don't know" answer, and as 1 for the correct answer. Total subscales score were calculated. A higher score indicated a higher level of knowledge. The average time taken to complete the questionnaire was 15 minutes.

Bergman et al. (24) examined the validity of the questionnaire using CFA, and found that the items were reduced from 82 items to a final 30 items, reflecting a five-factor model. Comparative fit index $(\mathrm{CFI})=0.82$, Tucker-Lewis index $(\mathrm{TLI})=0.88$, and root mean square error of approximation (RMSEA) $=0.03$ were reported for the CFA model. Thus, the five-factor model demonstrated a good-fit model based on RMSEA.

In the present study, two items did not reach a content validity index of 0.78 . These were questions pertaining to statement Q13 "Heart disease is the leading cause of death in the United States" and Q25 - "Margarine with liquid safflower oil is healthier than margarine with hydrogenated soy oil". Thus, the wording of the two items was revised to be more culturally appropriate, and altered accordingly to suit the Malaysian context. The wordings of items Q13 and Q25 were changed to "Heart disease is the leading cause of death in Malaysia" and "Margarine with liquid olive oil is healthier than margarine with hydrogenated palm oil" respectively. The adapted HDKQ was utilised in the present study.

\section{Ethical considerations}

Approval for the study was obtained from the Human Research Ethics Committee, USM. Participants were guaranteed anonymity and confidentiality for participating in the study, and were fully informed about its purpose. Implied consent was deemed to have given once the participants completed and returned the survey form.

\section{Data analysis}

Several type of software were used for the data analysis. Microsoft Excel (2013), IBM SPSS version 22 and Mplus version 7.3 (29) were used to conduct item analysis, descriptive analysis and CFA, respectively. There were no missing data values.

Descriptive statistics were calculated to describe the characteristics of the sample and the item analysis (the index of difficulty and item discrimination) of the scale. The validation of the factor structure of HDKQ was tested via CFA and construct validity. A $P$-value $<0.050$ (two-tailed) was regarded as statistically significant.

\section{Item analysis}

Item analysis involved statistical analysis, based on item level in a scale. It was used to identify which items could be retained or discarded (30). Item analysis was performed using the difficulty and discrimination indices.

The difficulty index was defined as the proportion of participants answering the item correctly, and was calculated by the number of correct responses over the total number of responses. Thus, the smaller the index, the more difficult the item is (30). An item within the range of $0.20-0.80$ was deemed to be acceptable (31).

The discrimination index was defined as the ability of the item to discriminate between students with high achievement and low achievement (32). It was calculated by dividing the participants into three groups according to their scores obtained on the knowledge measure as a whole: an upper group, consisting of $27 \%$ who answered the item correctly, a lower group, consisting of the $27 \%$ who answered the item correctly and a middle group consisting of the remaining $46 \%$, after the students had been ranked (32-34). 
Scoring for the discrimination index was as follows: > $0.40=$ very good items; $0.30-0.39=$ reasonably good, but possibly subject to improvement; $0.20-0.29=$ marginal items, and subject to improvement; and $<0.19=$ poor items, to be rejected or improved by revision (33). Items that did not fulfil the criteria of the difficulty and discrimination indices were still included in the CFA analysis, but were cautiously viewed as potentially problematic.

\section{Confirmatory Factor Analysis}

The weighted least squares mean and variance adjusted (WLSMV) estimator was used in the analysis. The WLSMV is a robust estimator of the weighted least squares in Mplus with regard to modelling categorical outcome (29).

To determine the factor structure of the adapted HDKQ, a number of fit indices were recommended: CFI $\geq 0.95$, TLI $\geq 0.95$, the weighted root mean square residual (WRMR) $\leq 1.00$, the RMSEA $<0.05$, or at most 0.08 and a non-significant WLSMV scaled chi-square difference test $\left(\Delta \chi^{2}\right.$ WLSMV) with degree of freedom (df) for the nested model (35-39). The CFA model was modified based on a modification index (MI) $>10$ of the additional specification of error covariance (40). Specifically, all deletions and modifications of item were carried out iteratively, based on insignificant factor loadings and poor item analysis until the model fit indices met the established criteria.

Discriminant validity was examined using the correlation among constructs $(r \leq 0.85)$. The discriminant validity could be established when items from the different constructs did not correlate with one another (41), or when a construct did not correlate with other constructs in a scale (35).

\section{Results}

\section{Socio-demographical characteristics}

Seven hundred and eighty-eight students were recruited. The socio-demographic characteristics of the undergraduate students are shown in Table 1 . The sample was primarily female (71\%) with mean [standard deviation (SD)] age of 20.2 (1.02) years, and ranging from 19-27 years.

\section{Heart Disease Knowledge Questionnaire responses}

As seen in Table 2, 30 questions were assessed, and the correct response to each item in the subscales presented as frequency and percentage. The mean (SD) score of the correct responses was 15.0 (3.79) over a total number of 30 questions.

\section{Item analysis}

The psychometric properties of the HDKQ by item level are given in Table 3. The difficulty index for most items was satisfactory (ranging from 0.12-0.91). Some items did not fall within the range of $0.20-0.80$ (Q8, Q10, Q11, Q17, Q20, Q24, and Q30). However, they were retained for further deletion during the CFA stage. According to the discrimination index, some items scored poorly and needed further improvement (Q8, Q10, Q14, Q17, Q20, Q22, and Q24). All items that did not meet the acceptable levels of difficulty and discrimination indices were retained in the subsequent CFA analyses but were view as potentially problematic.

\section{Confirmatory factor analysis}

CFA was subsequently applied to the data in order to determine how well the hypothesised five-factor model fit the data obtained. The initial model displayed a poor fit of data for a five-factor model, with 30 items. The CFI (0.71), TLI (o.68) and WRMR (1.30) were not within the acceptable threshold. The only exception in this regard was RMSEA (0.032) [90\% confidence interval (CI): $0.03,0.04$ and close-fit $P$-value $=>0.950]$.

It was found on examination of each item's standardised factor loading that three items (Q8, Q10 and Q14) had a very low negative loadings ranging from -0.13 to -0.03 while four items (Q11, Q22, Q17 and Q24) did not produce significant estimates $(P$-value $>0.050)$ of their respective factors. Previously, these items Q8, Q10, Q11, Q17, Q20, Q24 and Q30 did not meet the difficulty index criteria, while items Q8, Q10, Q14, Q17, Q20, Q22 and Q24 did not meet the discrimination index criteria. Adequate theoretical support was applied to investigate these items, and a decision taken to remove them iteratively. Item Q20 and Q30 were not removed from the model because the factor loadings were found to be significant. 
Original Article | Psychometric properties of the heart disease knowledge scale

Table 1: Demographical data $(n=788)$

\begin{tabular}{lcc} 
Demographic variables & Frequency $(\mathbf{n})$ & Percentage (\%) \\
\hline Gender & 557 & 70.7 \\
Female & 231 & 29.3 \\
Male & & \\
\hline Ethnicity & 375 & 47.6 \\
Malay & 338 & 42.9 \\
Chinese & 48 & 6.1 \\
Indian & 27 & 3.4 \\
Others & & \\
\hline Living arrangement & 707 & 89.7 \\
On campus & 81 & 10.3 \\
Off campus & & \\
\hline School/Faculty & 133 & 16.9 \\
Health Sciences & 83 & 10.5 \\
Medical Sciences & 4 & 0.5 \\
Music & 161 & 20.4 \\
Management & 73 & 9.1 \\
Electric and Electronic Engineering & 49 & 6.2 \\
Mechanical Engineering & 184 & 23.4 \\
Pharmaceutical Sciences & 102 & 12.9 \\
Computer Science & & \\
\hline Fields of study & 165 & 20.9 \\
Arts & 401 & 50.9 \\
Sciences & 222 & 28.2 \\
Technical & & \\
\hline Year of study & 421 & 53.4 \\
First & 234 & 29.7 \\
Second & 133 & 16.9 \\
Third & &
\end{tabular}

Furthermore, an improvement in the fit indices was not observed when both items were removed iteratively. The subsequent modified model of knowledge consisted of a five-factor model with 23 items with fit indices: $\Delta \chi^{2}$ WLSMV (df) $=$ $13.79(4), P$-value $=0.008, \mathrm{CFI}=0.86, \mathrm{TLI}=$ $0.84, \mathrm{WRMR}=1.14, \mathrm{RMSEA}=0.03(90 \% \mathrm{CI}$ : $0.03,0.04$ and close-fit $P$-value $=>0.950)$. Thus, a better fit improvement was demonstrated with the subsequent modified model compared to the initial model. However, modification based on MI was not performed because a remarkable improvement in the fit indices was not observed.

The factors correlations for the modified five-factor model are presented in Table 4. Owing to high correlation between factors (risk factor and epidemiology), the model was revised to a four-factor model by combining the risk factor and epidemiology subscales. The four-factor model had factor correlations $r$, ranging from 0.43-0.97. The correlation between the factors was still high, and all the remaining 23 items were combined into a single-factor structure.

The single-factor structure CFA model fitted the data well based on several fit indices: $\Delta$ $\chi^{2}$ WLSMV $(\mathrm{df})=1.22(2), P$-value $=0.544$ and RMSEA $=0.03$ (90\% CI: 0.03, 0.04 and closefit $P$-value $=>0.950)$. A summary of the fit indices of the CFA models of HDKQ are shown in Table 5. The final model consisted of 23 items with significant factor loadings, ranging from 0.15-0.66 (Table 6). 
Table 2: The responses with correct answers (in bold) given to items on HDKQ ( $n=788)$

\begin{tabular}{|c|c|c|c|c|}
\hline $\begin{array}{l}\text { Item } \\
\text { number }\end{array}$ & Description & & Responses & \\
\hline & & True (\%) & False (\%) & $\begin{array}{l}\text { Don't know } \\
\text { (\%) }\end{array}$ \\
\hline \multicolumn{5}{|c|}{ Dietary knowledge } \\
\hline Q1 & $\begin{array}{l}\text { Polyunsaturated fats are healthier for the heart than saturated } \\
\text { fats. }\end{array}$ & $394(50)$ & $92(11.7)$ & $302(38.3)$ \\
\hline Q6 & $\begin{array}{l}\text { Trans-fats are healthier for the heart than most other kinds } \\
\text { of fats. }\end{array}$ & $212(26.9)$ & $262(33.1)$ & $315(40)$ \\
\hline Q9 & Most of the cholesterol in an egg is in the white part of the egg. & $115(14.6)$ & $585(74.2)$ & $88(11.2)$ \\
\hline Q12 & Dietary fiber lowers blood cholesterol. & $514(65.2)$ & $71(9.0)$ & $203(25.8)$ \\
\hline Q25 & $\begin{array}{l}\text { Margarine with liquid olive oil is healthier than margarine } \\
\text { with hydrogenated palm oil. }\end{array}$ & $486(61.7)$ & $77(9.8)$ & $225(28.6)$ \\
\hline Q30 & Many vegetables are high in cholesterol. & $35(4.4)$ & $683(86.7)$ & $70(8.9)$ \\
\hline \multicolumn{5}{|c|}{ Epidemiology knowledge } \\
\hline Q2 & $\begin{array}{l}\text { Women are less likely to get heart disease after menopause } \\
\text { than before. }\end{array}$ & $151(19.2)$ & $270(34 \cdot 3)$ & $367(46.6)$ \\
\hline Q13 & Heart disease is the leading cause of death in Malaysia. & $623(79.1)$ & $74(9.4)$ & $91(11.5)$ \\
\hline Q24 & $\begin{array}{l}\text { Most women are more likely to die from breast cancer than } \\
\text { heart disease. }\end{array}$ & $443(56.2)$ & 148 (18.8) & $197(25.0)$ \\
\hline Q29 & $\begin{array}{l}\text { Heart disease is better defined as a short-term illness than a } \\
\text { chronic, long-term illness. }\end{array}$ & $139(17.6)$ & $464(58.9)$ & $185(23.5)$ \\
\hline \multicolumn{5}{|c|}{ Risk factor knowledge } \\
\hline Q3 & $\begin{array}{l}\text { Having had chicken pox increases the risk of getting heart } \\
\text { disease. }\end{array}$ & $51(6.5)$ & $413(52.4)$ & $324(41.1)$ \\
\hline Q4 & Eating a lot of red meat increases heart disease risk. & $551(69.9)$ & $110(14.0)$ & $127(16.1)$ \\
\hline Q7 & The most important cause of heart attack is stress. & $436(55 \cdot 3)$ & $268(34.0)$ & $84(10.7)$ \\
\hline Q8 & $\begin{array}{l}\text { Walking and gardening are considered types of exercise that } \\
\text { can lower heart disease risk. }\end{array}$ & $720(91.4)$ & $35(4.4)$ & $33(4.2)$ \\
\hline Q10 & $\begin{array}{l}\text { Smokers are more likely to die of lung cancer than heart } \\
\text { disease. }\end{array}$ & $606(76.9)$ & 95 (12.1) & $87(11.0)$ \\
\hline Q11 & $\begin{array}{l}\text { Taking an aspirin each decreases the risk of getting heart } \\
\text { disease. }\end{array}$ & $146(18.5)$ & $355(45.1)$ & $287(36.4)$ \\
\hline Q22 & Taller people are more at risk for getting heart disease. & $74(9.4)$ & $456(57.9)$ & $258(32.7)$ \\
\hline Q26 & $\begin{array}{l}\text { People who have diabetes are at higher risk of getting heart } \\
\text { disease. }\end{array}$ & $533(67.6)$ & $102(12.9)$ & $153(19.4)$ \\
\hline Q28 & $\begin{array}{l}\text { Eating a high fiber diet increases the risk of getting heart } \\
\text { disease. }\end{array}$ & $99(12.6)$ & $572(72.6)$ & $117(14.8)$ \\
\hline \multicolumn{5}{|c|}{ Medical knowledge } \\
\hline Q5 & $\begin{array}{l}\text { Most people can tell whether or not they have high blood } \\
\text { pressure. }\end{array}$ & $357(45 \cdot 3)$ & $299(37.9)$ & $132(16.8)$ \\
\hline Q14 & $\begin{array}{l}\text { The healthiest exercise for the heart involves rapid breathing } \\
\text { for a sustained period of time. }\end{array}$ & $313(39.7)$ & $200(25.4)$ & $275(34.9)$ \\
\hline Q16 & $\begin{array}{l}\text { A healthiest person's pulse should return to normal within } 15 \\
\text { minutes after exercise. }\end{array}$ & $414(52.5)$ & $71(9.0)$ & $303(38.5)$ \\
\hline Q18 & $\begin{array}{l}\text { Cardiopulmonary resuscitation (CPR) helps to clear clogged } \\
\text { blood vessels. }\end{array}$ & $174(22.1)$ & $395(50.1)$ & $219(27.8)$ \\
\hline Q19 & $\begin{array}{l}\text { HDL refers to "good" cholesterol, and LDL refers to "bad" } \\
\text { cholesterol. }\end{array}$ & $376(47 \cdot 7)$ & $115(14.6)$ & $297(37.7)$ \\
\hline
\end{tabular}


Original Article | Psychometric properties of the heart disease knowledge scale

Table 2: (continued)

\begin{tabular}{|c|c|c|c|c|}
\hline \multirow[t]{2}{*}{$\begin{array}{l}\text { Item } \\
\text { number }\end{array}$} & \multirow[t]{2}{*}{ Description } & \multicolumn{3}{|c|}{ Responses } \\
\hline & & True (\%) & False (\%) & $\begin{array}{l}\text { Don't know } \\
\text { (\%) }\end{array}$ \\
\hline Q20 & $\begin{array}{l}\text { Atrial defibrillation is a procedure where hardened arteries } \\
\text { are opened to increase blood flow. }\end{array}$ & $280(35.5)$ & $81(10.3)$ & $427(54.2)$ \\
\hline Q23 & $\begin{array}{l}\text { "High" blood pressure is defined as 110/80 (systolic/diastolic) } \\
\text { or higher. }\end{array}$ & $192(24.4)$ & $386(49.0)$ & $210(26.6)$ \\
\hline \multicolumn{5}{|c|}{ Symptoms knowledge } \\
\hline Q15 & Turning pale or gray is a symptom of having a heart attack. & $330(41.9)$ & $151(19.2)$ & $307(39.0)$ \\
\hline Q17 & $\begin{array}{l}\text { Sudden trouble seeing in one eye is a common symptom of } \\
\text { having a heart attack. }\end{array}$ & $191(24.2)$ & $149(18.9)$ & $448(56.9)$ \\
\hline Q21 & $\begin{array}{l}\text { Feeling weak, lightheaded, or faint is a common symptom of } \\
\text { having a heart attack. }\end{array}$ & $439(55.7)$ & $177(22.5)$ & $172(21.8)$ \\
\hline Q27 & $\begin{array}{l}\text { Men and women experience many of the same symptom of a } \\
\text { heart attack. }\end{array}$ & $463(58.8)$ & $128(16.2)$ & $197(25.0)$ \\
\hline
\end{tabular}

$\mathrm{Q}=$ Question number.

Table 3:Psychometric properties of HDKQ by item level $(n=788)$

\begin{tabular}{lcc} 
Item & $\begin{array}{c}\text { Difficulty } \\
\text { index }\end{array}$ & $\begin{array}{c}\text { Discrimination } \\
\text { index }\end{array}$ \\
\hline Q1 & 0.50 & 0.49 \\
Q2 & 0.34 & 0.41 \\
Q3 & 0.52 & 0.29 \\
Q4 & 0.70 & 0.29 \\
Q5 & 0.38 & 0.36 \\
Q6 & 0.33 & 0.43 \\
Q7 & 0.34 & 0.29 \\
Q8 & 0.91 & 0.03 \\
Q9 & 0.74 & 0.41 \\
Q10 & 0.12 & 0.05 \\
Q11 & 0.19 & 0.15 \\
Q12 & 0.65 & 0.38 \\
Q13 & 0.79 & 0.24 \\
Q14 & 0.40 & 0.11 \\
Q15 & 0.42 & 0.37 \\
\hline & & (continued)
\end{tabular}

Table 3: (continued)

\begin{tabular}{ccc}
\hline Item & $\begin{array}{c}\text { Difficulty } \\
\text { index }\end{array}$ & $\begin{array}{c}\text { Discrimination } \\
\text { index }\end{array}$ \\
\hline Q16 & 0.53 & 0.36 \\
Q17 & 0.19 & 0.13 \\
Q18 & 0.50 & 0.47 \\
Q19 & 0.48 & 0.52 \\
Q20 & 0.10 & 0.11 \\
Q21 & 0.56 & 0.33 \\
Q22 & 0.58 & 0.16 \\
Q23 & 0.49 & 0.46 \\
Q24 & 0.19 & 0.10 \\
Q25 & 0.62 & 0.46 \\
Q26 & 0.68 & 0.30 \\
Q27 & 0.59 & 0.37 \\
Q28 & 0.73 & 0.50 \\
Q29 & 0.59 & 0.41 \\
Q30 & 0.87 & 0.24 \\
\hline Q = Question number &
\end{tabular}


Table 4: Model fit indices of the HDKQ measurement models

\begin{tabular}{|c|c|c|c|c|c|c|c|c|}
\hline \multirow[t]{2}{*}{ Model } & \multicolumn{3}{|l|}{$\Delta$ Chi-square $^{\mathrm{a}}$} & \multirow[t]{2}{*}{ CFI } & \multirow[t]{2}{*}{ TLI } & \multirow[t]{2}{*}{ WRMR } & \multirow{2}{*}{$\begin{array}{l}\text { RMSEA }(90 \% \\
\text { CI) }\end{array}$} & \multirow[t]{2}{*}{$\begin{array}{l}\text { Clfit } \\
P \text {-value } \\
\end{array}$} \\
\hline & LSMV & df & $P$-value & & & & & \\
\hline Initial & - & - & - & 0.708 & 0.679 & 1.299 & $\begin{array}{l}0.032(0.028 \\
0.036)\end{array}$ & $>0.950$ \\
\hline $\begin{array}{l}5 \text {-factor } \\
\text { modified }\end{array}$ & 13.793 & 4 & 0.008 & 0.857 & 0.836 & 1.140 & $\begin{array}{l}0.031(0.026 \\
0.036)\end{array}$ & $>0.950$ \\
\hline 4-factor & 7.299 & 3 & 0.063 & 0.858 & 0.840 & 1.145 & $\begin{array}{l}0.031(0.025 \\
0.036)\end{array}$ & $>0.950$ \\
\hline 1-factor & 1.219 & 2 & 0.544 & 0.848 & 0.833 & 1.173 & $\begin{array}{l}0.031(0.026, \\
0.036)\end{array}$ & 0.950 \\
\hline
\end{tabular}

${ }^{a}$ WLSMV scaled difference chi-square test, $\mathrm{df}=$ degree of freedom, CFI = Comparative fit index, TLI = Tucker-Lewis index, WRMR = Weighted root mean square residual, RMSEA = Root mean square error of approximation, Clfit = Close fit P-value for RMSEA.

Table 5: Standardised factor loadings $(\lambda)$ and probability value of the final model of HDKQ

\begin{tabular}{lcc}
\hline Item number & $\begin{array}{c}\text { Standardised factor loadings }(95 \% \\
\text { CI })\end{array}$ & P-value \\
\hline Q1 & $0.401(0.302,0.484)$ & $<0.001$ \\
Q2 & $0.349(0.247,0.435)$ & $<0.001$ \\
Q3 & $0.153(0.048,0.241)$ & 0.004 \\
Q4 & $0.256(0.153,0.342)$ & $<0.001$ \\
Q5 & $0.255(0.149,0.344)$ & $<0.001$ \\
Q6 & $0.445(0.345,0.528)$ & $<0.001$ \\
Q7 & $0.208(0.103,0.296)$ & $<0.001$ \\
Q9 & $0.496(0.399,0.578)$ & $<0.001$ \\
Q12 & $0.414(0.314,0.497)$ & $<0.001$ \\
Q13 & $0.249(0.137,0.343)$ & $<0.001$ \\
Q15 & $0.229(0.117,0.309)$ & $<0.001$ \\
Q16 & $0.216(0.113,0.302)$ & $<0.001$ \\
Q18 & $0.439(0.346,0.518)$ & $<0.001$ \\
Q19 & $0.547(0.459,0.621)$ & 0.001 \\
Q20 & $0.242(0.086,0.373)$ & $<0.001$ \\
Q21 & $0.208(0.105,0.294)$ & $<0.001$ \\
Q23 & $0.391(0.290,0.475)$ & $<0.001$ \\
Q25 & $0.458(0.364,0.536)$ & $<0.001$ \\
Q26 & $0.221(0.115,0.311)$ & $<0.001$ \\
Q27 & $0.282(0.180,0.367)$ & $<0.001$ \\
Q28 & $0.658(0.573,0.730)$ & $<0.001$ \\
Q29 & $0.400(0.304,0.481)$ & $<0.001$ \\
Q30 & $0.538(0.425,0.634)$ & \\
\hline Q & & \\
\hline
\end{tabular}

$\mathrm{Q}=$ Question number, $\mathrm{CI}=$ Confidence Interval. 
Original Article | Psychometric properties of the heart disease knowledge scale

Table 6: Factor correlations for the modified five-factor model

\begin{tabular}{lcc} 
Factor pairs & \begin{tabular}{c} 
Correlations, \\
\multicolumn{1}{c}{$\boldsymbol{P}$-value }
\end{tabular} \\
\hline $\begin{array}{l}\text { Dietary-Risk } \\
\text { Factor }\end{array}$ & 0.937 & $<0.001$ \\
$\begin{array}{l}\text { Epidemiology- } \\
\text { Risk Factor }\end{array}$ & 1.062 & $<0.001$ \\
$\begin{array}{l}\text { Epidemiology - } \\
\text { Dietary }\end{array}$ & 0.884 & $<0.001$ \\
$\begin{array}{l}\text { Medical -Risk } \\
\text { Factor }\end{array}$ & 0.910 & $<0.001$ \\
$\begin{array}{l}\text { Medical - } \\
\text { Epidemiology }\end{array}$ & 1.130 & $<0.001$ \\
$\begin{array}{l}\text { Medical - } \\
\text { Dietary }\end{array}$ & 0.940 & $<0.001$ \\
$\begin{array}{l}\text { Symptoms - } \\
\text { Risk Factor }\end{array}$ & 0.543 & $<0.001$ \\
$\begin{array}{l}\text { Symptoms - } \\
\text { Dietary }\end{array}$ & 0.484 & $<0.001$ \\
$\begin{array}{l}\text { Symptoms - } \\
\text { Epidemiology }\end{array}$ & 0.737 & $<0.001$ \\
$\begin{array}{l}\text { Symptoms - } \\
\text { Medical }\end{array}$ & 0.439 & $<0.001$ \\
\hline
\end{tabular}

\section{Discussion}

This study illustrated the application of two approaches in determining the psychometric properties of the adapted HDKQ, namely item analysis and the CFA. The study findings provided evidence that the adapted HDKQ inventory have adequate levels of psychometric properties based on item and scale levels to measure the knowledge of heart disease among Malaysian undergraduate students.

The findings of both the difficulty and discrimination indices indicated that the adapted HDKQ inventory was satisfactory. The wide scatter of item discrimination values for items with a similar level of difficulty may reflect that, to some extent, undergraduate students guessed when answering question on heart disease knowledge. Poor scores for the discrimination and difficulty indices were obtained for Q20 and a poor difficulty index score for Q30. Nevertheless, a decision to retain these items after the CFA stage was taken because the procedure of atrial defibrillation in medical knowledge (Q20) and the importance of vegetable consumption for heart disease prevention (Q30) constitute core information on heart disease.
Perhaps, in addition to poor medical knowledge of heart disease, the low score obtained for Q20 related to vocabulary skills. However, it must be recognised other factors need to be taken into account when using discrimination indices to categorise HDKQ inventory as either "good" or "bad", especially when dealing with a multidisciplinary undergraduate students. For example, students' performance with respect to HDKQ items on nutrition knowledge of heart disease may not be accurately predictive of their performance of with respect to HDKQ items on another domain e.g. medical knowledge, or with regard to their overall performance in the total HDKQ test score.

The advantage of performing item analysis was the ability to flag the poor performing item. It is also used to ensure determine the quality of the item (42) for further analysis. Interestingly, a wide scatter of difficulty index scores was obtained in our study. Seven items were either $\leq 0.20$ or $\geq$ o.80, when compared to the scores obtained in the study by Bergman et al. (24), in which only one item have poor difficulty index of $\leq 0.20$. This may be owing to the sample characteristics of the present study, which included university students of differing backgrounds and different field of studies.

WLSMV was used in our study because the HDKQ has a binary categorical outcome. WLSMV provides the identical parameter estimate and standard error like those of the maximum likehood estimator, a common estimator in CFA analysis $(39,43)$. Furthermore, minimal assumptions about the distribution of the observed variable are required using the WLS method, and it also produces accurate chi-square statistics and standard errors if the sample size is sufficiently large (38).

A five-factor model with 30 items was cited in the original HDKQ inventory (24). However, this was not supported, based on the present findings. The CFA result revealed a final 23item, one-factor model of HDKQ inventory, with the elimination of other poor performing items (Q8, Q10, Q11, Q14, Q17, Q22 and Q24) in the CFA stage. The poor items were revisited in the CFA stage for further deletion to ensure that the inventory demonstrated coherence between the data and the structure based on the fit indices criteria.

An adequate model fit was shown in the final CFA model and can presently be considered to be the best validated scale. The five-factor model was relapsed and combined as a single factor model, which fit the data well, based on the $\Delta \chi^{2}$ WLSMV 
and RMSEA indices. The single-factor model was more logically sound, informative and meaningful than a five- or four-factor model as the other indices, i.e., TLI, CFI and WRMR, demonstrated weak support for model fitness. Furthermore, the TLI and CFI values in the present findings were also similar to those obtained in the study by Bergman et al. (24), with TLI and CFI falling below the recommended criteria.

With respect to discriminant validity, six pairs of factors demonstrated high correlation $(r>0.85)$, i.e., diet-risk factor, epidemiologyrisk factor, epidemiology-diet, medical-risk factor, medical-epidemiology and medicaldiet (Table 4). According to Brown (41), when factors overlap to this degree $(r>0.85)$, it may be possible to combine the factors to acquire a more parsimonious solution. As shown in Table 6 , the standardised factor loadings were found to be lower than those suggested by Ford et al. (44) but the factor loading the range was higher than that reported by Bergman et al. (24). A factor loading of $\geq 0.40$ was found for 10 of the 23 items in the present study. Thus, the final CFA model was revised to a single-factor model with an improvement in the $\Delta \chi^{2}$ WLSMV and RMSEA indices.

\section{Limitations}

There were a number of potential limitations to this study. While the sample was randomly selected, selection bias was possible owing to the unequal proportion of students in different fields of study and their gender (mostly females). These confounding variables should have been controlled during the baseline comparison.

Furthermore, the study population derived mainly from one university. Therefore, it can only be generalised to undergraduate students studying in USM until further cross-cultural validation study are conducted at other universities in Malaysia to confirm these findings. The students may have not been familiar with the contents of the HDKQ, and this might have led them to response bias as the participants came from different fields of study. However, young adults should always be targeted when promoting cardiovascular health as they are our future assets.

\section{Conclusion}

It was shown in the present study that the 23item, single-factor model of the HDKQ inventory has adequate levels of psychometric properties. It is a refined measure of heart disease knowledge that covers a wide range of knowledge concepts, and is presently considered to be the best validated scale among Malaysian undergraduate students.

In practice, this instrument may be used to assess knowledge about heart disease among young adults, and provide useful insight for professional healthcare providers, nursing educators, policy-makers and lecturers who are promoting cardiovascular health in university for early preventive behaviours among young adults. More emphasis should be placed on ensuring that young adults effectively improve their knowledge about heart disease and engaging healthier lifestyle activities during their university years.

The present study could have been improved via the application of the item response theory (IRT). According to Wilson et al. (45), IRT is a behaviour change assessment that utilises a model-based approach to a measurement for each item as a probability of a correct response in participants' latent trait e.g. true heart disease knowledge.

Future studies should also include samples from other universities for cross-cultural validation studies via multi-group CFA test such as gender (e.g. male or female), fields of study (e.g. arts or science or technical) and student groupings (e.g. undergraduate or postgraduate) and to examine the stability properties of the adapted HDKQ instrument through the testretest method. Ultimately, there is a need for a qualitative study to examine how well this measure assesses all relevant facets of the construct of HDKQ inventory among undergraduate students.

\section{Acknowledgements}

This study would not have been possible without the support from the Universiti Sains Malaysia, and all the individuals directly or indirectly involved in this study, specifically to participants who gave so generously of their time to participate in this study.

\section{Conflict of Interest}

\section{No}

\section{Funds}

No

\section{Authors' Contributions}

Conception and design, provision of study materials, collection and assembly of the data, statistical expertise, administrative, technical, or logistics, analysis and interpretation of the data, and drafting of the article, 
Original Article | Psychometric properties of the heart disease knowledge scale

final approval of the article: BCL

Statistical expertise, critical revision of the article for intellectual content, and final approval of the article: YCK, WNA, and KHN

\section{Correspondence}

Dr. Kueh Yee Cheng

MSc (Medical Statistics), PhD (Biostatistics)

Unit of Biostatistics and Research Methodology,

School of Medical Sciences, Universiti Sains Malaysia, 16150 Kubang Kerian, Kelantan, Malaysia

Tel: +6 09-767 6159

Fax: +609-765 3370

E-mail:yckueh@usm.my

\section{References}

1. American Heart Association. Heart Disease and Stroke Statistics - At a glance [Internet]; 2015 [cited 29 Aug 2015]. Available from: http://www.heart.org/ idc/groups/ahamah-public/@wcm/@sop/@smd/ documents/downloadable/ucm_470704.pdf.

2. The Heart Foundation of Malaysia. The Heart Foundation of Malaysia [Internet]; 1999-2015 [cited 31 Aug 2015]. Available from: http://www.yjm.org. my/index.cfm?menuid=2.

3. Department of Statistics Malaysia. Statistics on causes of death Malaysia 2008. Putrajaya: Department of Statistics Malaysia; 2010.

4. Ministry of Health Malaysia. Health facts 2013. Putrajaya: Health Informatics Centre Planning and Development Division; 2013.

5. Aglony M, Acevedo M, Ambrosio G. Hypertension in adolescents. Expert Rev Cardiovasc Ther. 2009;7(12):1595-1603. doi: http://dx.doi. org/10.1586/erc.09.150

6. Ogden CL, Carroll MD, Curtin LR, McDowell MA, Tabak CJ, Flegal KM. Prevalence of overweight and obesity in the United States, 1999-2004. JAMA. 2006;295(13):1549-1555. doi: http://dx.doi. org/10.1001/jama.295.13.1549

7. Din-Dzietham R, Liu Y, Bielo MV, Shamsa F. High blood pressure trends in children and adolescents in national surveys, 1963 to 2002. Circulation. 2007;116:1488-1496. doi: http://dx.doi.org/10.1161/ CIRCULATIONAHA.106.683243

8. Rampal L, Ng KC, Nur Izzati I, Farah Izzati Z, Mohammad Nazrul I, Faisal I, et al. Prevalence of hypertension among Malay adolescents in Putrajaya secondary schools, Malaysia, 2010. Malaysian Journal of Medicine and Health Sciences. 2011;7(2):53-60.

9. Muntner P, Jiang H, Cutler JA, Wildman RP, Whelton PK. Trends in blood pressure among children and adolescents. JAMA. 2004;291:2107-2113. doi: http://dx.doi.org/10.1001/jama.291.17.2107

10. Strong JP, Malcom GT, McMahan CA, Tracy RE, Newman III WP, Herderick EE, et al. Prevalence and extent of atherosclerosis in adolescents and young adults: implications for prevention from the pathobiological determinants of atherosclerosis in youth study. JAMA. 1999;281(8):727-735. doi: http://dx.doi.org/10.1001/jama.281.8.727

11. Berenson GS. Cardiovascular risk begins in childhood: A time for action. Am $J$ Prev Med. 2009;37 (Supplement 1):S1-S2. doi: http://dx.doi. org/10.1016/j.amepre.2009.04.018

12. Hunt DP. The concept of knowledge and how to measure it. Journal of Intellectual Capital. 2003;4(1):100-113. doi: http://dx.doi.org/10.1108/ 14691930310455414

13. Homko CJ, Santamore WP, Zamora L, Shirk G, Gaughan J, Cross R, et al. Cardiovascular disease knowledge and risk perception among underserved individuals at increased risk of cardiovascular disease. $J$ Cardiovasc Nurs. 2008;23(4):332-337. doi: 10.1097/01.JCN.ooo0317432.44586.aa. http:// dx.doi.org/10.1097/01.JCN.0000317432.44586.aa

14. Chan CW, Lopez V, Chung JW. A survey of coronary heart disease knowledge in a sample of Hong Kong Chinese. Asia Pac J Public Health. 2011;23(3):288-297. doi: http://dx.doi.org/10.1177/ 1010539509345869

15. Gautam YR. A study of assessing knowledge and health beliefs about cardiovascular disease among selected undergraduate students using health belief model. [PhD Degree]. [Carbondale]: Southern IIlinois University; 2012.

16. Vanhecke TE, Miller WM, Franklin BA, Weber JE, McCullough PA. Awareness, knowledge, and perception of heart disease among adolescents. Eur J Cardiovasc Prev Rehabil. 2006;13:718-723. doi: http://dx.doi.org/10.1097/o1.hjr.0000214611. 91490.5e

17. Collins KM, Dantico M, Shearer NB, Mossman KL. Heart disease awareness among college students. Journal of Community Health. 2004;29(5):405420. doi: http://dx.doi.org/10.1023/B:JOHE. 0000038655.19448.b2

18. Wagner J, Lacey K, Chyun D, Abbott G. Development of a questionnaire to measure heart disease risk knowledge in people with diabetes: The heart disease fact questionnaire. Patient Educ Couns. 2005;58:82-87. doi: http://dx.doi.org/10.1016/j. pec.2004.07.004

19. Yadav KD, Wagle RR. Knowledge and attittude regarding major risk factors of cardiovascular diseases among 15-19 year old students of Khatmandu district. Health Prospect. 2012;11:7-10. doi: http://dx.doi. org/10.3126/hprospect.v11io.7422

20. Vaidya A, Aryal UR, Krettek A. Cardiovascular health knowledge, attitude and practice/behaviour in an urbanising community of Nepal: A popoulationbased cross-sectional study from Jhaukhel-Duwakot health demographic surveillance site. BMJ Open. 2013;3:e002976. doi: http://dx.doi.org/10.1136/ bmjopen-2013-002976

21. Winham DM, Jones KM. Knowledge of young African Amercian adults about heart diease: A cross sectional 
survey. BMC Public Health. 2012;11:248-258. doi: http://dx.doi.org/10.1186/1471-2458-11-248

22. Amin AM, Hamza M, Azmi S. Factors associated with the general public knowledge and awareness of cardiovascular diseases and its risk factors in Penang - Malaysia. ISOR Journal of Pharm. 2014;4(6):2127. doi: http://dx.doi.org/10.9790/30130406010210271.

23. Muhamad R, Yahya R, Mohamed Yusoff $\mathrm{H}$. Knowledge, attitude and practice on cardiovascular disease among women in north-eastcoast Malaysia. International Int $J$ Collab Res Intern Med Public Health [Internet]; 2012 [cited 31 Aug 2014];4(1):8598. Available from: http://iomcworld.com/ijcrimph/ ijcrimph-v04-no1-o8.htm.

24. Bergman HE, Reeve BB, Moser RP, Scholl S, Klein WMP. Development of a comprehensive heart disease knowledge questionnaire. Am J Health Educ. [Internet]. 2011 [cited 26 Aug 2014];42(2):74-87. Available from: http://files.eric.ed.gov/fulltext/ EJ918449.pdf.

25. Raykov $\mathrm{T}$, Marcoulides GA. Introduction to psychometric theory. New York: Taylor and Francis Group; 2011.

26. Streiner DL, Norman, GR. Health measurement scales: A practical guide to their development and use. 4th ed. New York: Oxford University Press; 2008. doi: http://dx.doi.org/10.1093/acprof:o so/9780199231881.001.0001

27. Fletcher RH, Fletcher SW, Wagner EH. Clinical epidemiology: The essentials. 3rd ed. Maryland: Williams \& Wilkins; 1996.

28. Romero DC, Sauris A, Rodriguez F, Delgado D, Reddy A, Foody JM. Vivir Con Un Corazón Saludable: a Community-Based Educational Program Aimed at Increasing Cardiovascular Health Knowledge in High-Risk Hispanic Women. J Racial Ethn Health Disparities. 2015;3(1):99-107. doi: http://dx.doi. org/10.1007/s40615-015-0119-6

29. Muthen LK, Muthen BO. Mplus user's guide. 7th ed. Los Angeles, CA: Muthen \& Muthen; 1998-2012.

30. Nunnally JC, Bernstein IH. Psychometric theory. 3rd ed. New York, NY: McGraw-Hill; 1994.

31. Kline P. The handbook of psychological testing. London: Routledge; 1993.

32. Linn RL, Grolund NE. Measurement and assessment in teaching. 7th ed. New Jersey: Prentice-Hall; 1995.

33. Ebel RL, Fresbie DA. Essentials of educational measurement. 5th ed. New Jersey: Prentice-Hall; 1991.
34. Abdul Rahim AF. What those numbers mean a guide to item analysis; 2010 [cited 19 Aug 2015]. Available from: http://www.medic.usm.my/dme/index. php?option $=$ com_content\&task=view\&id=54\&Item id $=86$.

35. Hair JFJ, Black WC, Babin BJ, Anderson RE. Multivariate data analysis. 7th ed. New Jersey: Pearson Prentice Hall; 2010.

36. Yu CY. Evaluating cutoff criteria of model fit Indices for latent variable models with binary and continuous outcomes. [PhD Degree]. [Los Angeles, CA]: University of California; 2002.

37. Kline RB. Principles and practice of structural equation modeling. 3rd ed. New York: The Guilford Press; 2011.

38. Schermelleh-Engel K, Moosbrugger $\mathrm{H}$, Muller $\mathrm{H}$. Evaluating the fit of structural equation models:Tests of significance and descriptive goodness-of-fit measures. Methods of Psychological Research Online [Internet]. 2003 [cited 26 August 2015];8(2):23-74. Available from: http://www.dgps.de/fachgruppen/ methoden/mpr-online/issue20/art2/mpr130_13. pdf.

39. Wang J, Wang X. Structural equation modeling applications using Mplus. Chichester, West Sussex, United Kingdom: John Wiley \& Sons Ltd.; 2012. doi: http://dx.doi.org/10.1002/9781118356258

40. Bryne BM. Structural equation modeling with AMOS basic concepts, applications, and programming. 2nd ed. New York: Taylor and Francis Group, LLC.; 2010.

41. Brown TA. Confirmatory factor analysis for applied research. New York: The Guilford Press; 2006.

42. Zurawsk RM. Making the most of exams: Procedures for item analysis. [Internet] 1996-1999. [cited 29 Aug 2015]. Available from: http://faculty.mansfield.edu/ lfeil/201/item-analysis-explained.htm.

43. Muthen BO. Mplus technical appendices. Los Angeles, CA: Muthen \& Muthen; 1998-2004.

44. Ford JK, MacCallum RC, Tait M. The application of exploratory factor annalysis in applied psychology: A critical review and analysis. Pers Psychol. 1986;39(2):291-314. doi: http://dx.doi. org/10.1111/j.1744-6570.1986.tboo583.x

45. Wilson M, Allen DD, Li JC. Improving measurement in health education and health behaviour research using item response item response modelling: Comparison with the classical test theory approach. Health Educ Res. 2006;21:119-132. doi: http:// dx.doi.org/10.1093/her/cylo53 
Original Article | Psychometric properties of the heart disease knowledge scale

\section{Appendix}

\section{Description of the questionnaire}

\begin{tabular}{|c|c|}
\hline Item number & Description \\
\hline \multicolumn{2}{|c|}{ Dietary knowledge } \\
\hline Q1 & Polyunsaturated fats are healthier for the heart than saturated fats. \\
\hline Q6 & Trans-fats are healthier for the heart than most other kinds of fats. \\
\hline Q9 & Most of the cholesterol in an egg is in the white part of the egg. \\
\hline Q12 & Dietary fiber lowers blood cholesterol. \\
\hline Q25 & Margarine with liquid olive oil is healthier than margarine with hydrogenated palm oil. \\
\hline Q30 & Many vegetables are high in cholesterol. \\
\hline \multicolumn{2}{|c|}{ Epidemiology knowledge } \\
\hline Q2 & Women are less likely to get heart disease after menopause than before. \\
\hline Q13 & Heart disease is the leading cause of death in Malaysia. \\
\hline Q24 & Most women are more likely to die from breast cancer than heart disease. \\
\hline Q29 & Heart disease is better defined as a short-term illness than a chronic, long-term illness. \\
\hline \multicolumn{2}{|c|}{ Risk factor knowledge } \\
\hline Q3 & Having had chicken pox increases the risk of getting heart disease. \\
\hline Q4 & Eating a lot of red meat increases heart disease risk. \\
\hline Q7 & The most important cause of heart attack is stress. \\
\hline Q8 & Walking and gardening are considered types of exercise that can lower heart disease risk. \\
\hline Q10 & Smokers are more likely to die of lung cancer than heart disease. \\
\hline Q11 & Taking an aspirin each decreases the risk of getting heart disease. \\
\hline Q22 & Taller people are more at risk for getting heart disease. \\
\hline Q26 & People who have diabetes are at higher risk of getting heart disease. \\
\hline Q28 & Eating a high fiber diet increases the risk of getting heart disease. \\
\hline \multicolumn{2}{|c|}{ Medical knowledge } \\
\hline Q5 & Most people can tell whether or not they have high blood pressure. \\
\hline Q14 & $\begin{array}{l}\text { The healthiest exercise for the heart involves rapid breathing for a sustained period of } \\
\text { time. }\end{array}$ \\
\hline Q16 & A healthiest person's pulse should return to normal within 15 minutes after exercise. \\
\hline Q18 & Cardiopulmonary resuscitation (CPR) helps to clear clogged blood vessels. \\
\hline Q19 & HDL refers to "good" cholesterol, and LDL refers to "bad" cholesterol. \\
\hline Q20 & $\begin{array}{l}\text { Atrial defibrillation is a procedure where hardened arteries are opened to increase blood } \\
\text { flow. }\end{array}$ \\
\hline Q23 & "High" blood pressure is defined as 110/80 (systolic/diastolic) or higher. \\
\hline \multicolumn{2}{|c|}{ Symptoms knowledge } \\
\hline Q15 & Turning pale or gray is a symptom of having a heart attack. \\
\hline Q17 & Sudden trouble seeing in one eye is a common symptom of having a heart attack. \\
\hline Q21 & Feeling weak, lightheaded, or faint is a common symptom of having a heart attack. \\
\hline Q27 & Men and women experience many of the same symptom of a heart attack. \\
\hline
\end{tabular}

$\mathrm{Q}=$ Question number. 